\title{
Advanced ML and AI Approaches for Proxy-based Optimization of CO2-Enhanced Oil Recovery in Heterogeneous Clastic Reservoirs
}

\author{
Watheq J. Al-Mudhafar ${ }^{1,2, *}$, Dandina N. Rao ${ }^{3}$, Sanjay Srinivasan ${ }^{4}$ \\ This is an as-yet, no peer-reviewed preprint that has been submitted to Fuel
}

\begin{abstract}
The EOS-compositional reservoir simulation, Design of Experiments, and Proxy Modeling were integrated to obtain the optimal future performance scenario and to construct the most accurate simplified model alternative to the complex reservoir flow simulation. This integrated workflow was adopted on a sector of the main pay/upper sandstone member in the South Rumaila oil field, located in Iraq. After conducting the acceptable history matching, 6 operational decision parameters, which constrain the production and injection activities, were optimized for their optimal level to achieve optimal flow response factor. Given these decision parameters, the Latin Hypercube Sampling was employed as a low-discrepancy and uniform approach to create hundreds of simulation runs (experiments) to construct a proxy-based optimization approach. The optimal cumulative oil production, by the end of the prediction period, led to obtaining 4.6039 MMMSTB of oil production, while the base case of the GAGD process evaluation of default parameters' setting resulted to obtain 4.3887 MMMSTB of oil production.

Finally, four proxy metamodels were constructed to provide simplified models alternative to the complex compositional reservoir simulation: Second-Degree Polynomial Equation (QM), Multivariate Additive Regression Splines (MARS), Fuzzy Logic-Genetic Algorithm (FUzzy-GEnetic), and Generalized Boosted Modeling (GBM). The cross-validation with Adjusted $R_{a d j}^{2}$ and Root Mean Square Error were employed to find the optimal proxy model that has the least mismatch between the proxy- and simulator-based cumulative oil production response through CO2-GAGD process. It was concluded that both GBM and FUzzy-GEnetic are the most accurate simplified alternative metamodels for the GAGD Process evaluation and prediction.
\end{abstract}

Keywords: Proxy Metamodeling, Design of Experiments, Cross-validation, Gravity Drainage, Enhanced Oil Recovery, Clastic Oil Reservoirs

\footnotetext{
*Corresponding author

Email address: watheq.almudhafar@utexas.edu, Tel:+1-225-715-2578 (Watheq J. Al-Mudhafar)

${ }^{1}$ Research Advisor, Adaptive GeoEnergy Research Center

${ }^{2}$ Chief Reservoir Engineer, Basrah Oil Company

${ }^{3}$ Professor, Louisiana State University

${ }^{4}$ Professor, Penn State University
} 


\section{Introduction}

Energy consumption worldwide is vastly increasing annually due to the technology revolution and the population significant incrimination. Discoveries of new oil fields have become rare in the last decade. Therefore, boosting oil production by utilizing all available technological methods s including Enhanced Oil Recovery methods (EOR) is inevitable. Specifically, Enhanced oil recovery is becoming more important than ever, as finding new sources are becoming more cost and time consuming, especially when the oil price is facing huge reduction. Gas flooding is considered one of the most promising technologies used in EOR projects. Gas flooding is being implemented through the Continuous Gas Injection (CGI) or Water-Alternating-Gas (WAG) processes. However, the GasAssisted Gravity Drainage (GAGD) process has recently been introduced to improved oil recovery in secondary and tertiary modes for both immiscible and miscible gas flooding processes (Rao , 2012). Therefore, it was suggested to enhance oil recovery in the main pay of Zubair formation in South Rumaila oil field, located in Iraq. That field was selected because it is a mature oil field that has been producing for more than 60 years and waterflooding is no longer effective to improve the recovery of oil.

Optimization of oil recovery, through the gas flooding, is a crucial task in the field development through Enhanced Oil Recovery (EOR) projects, especially when conducted in real oil fields. There are many parameters that affect the reservoir performance through the CO2-EOR processes. Some of these parameters are operational or controllable by field operators, such as the well production and injection constraints. Some other factors are uncontrollable, such as the geological properties. These operational factors need to be optimized in order to determine the optimal solution of the reservoir flow response. It is essential to determine the optimal levels of the operational decision factors that impact the Enhanced Oil Recovery process' performance. These factors are mainly comprised of operational constraints in production and injection wells. More specifically, the manner in which the jection and production constraints are set controls the amount of fluid production and injection in the reservoir; thus, providing a direct impact on the reservoir flow response. Therefore, the optimization of these factors obtains the optimal reservoir performance over time with respect to field cumulative oil production and Net Present Value (NPV) (White and Royer , 2003).

The Design of Experiments (DoE) and proxy modeling approaches are combined to construct a Response Surface Methodology (RSM) as a simplified alternative surrogate or metamodel for the complex models to evaluate the various designed experiments in the optimization procedure rather than the simulator itself (Lee et al. , 2003). The proxy modeling optimization has never been found in the literature regarding the CO2-GAGD process. However, the proxy model has been adopted in various reservoir studies and EOR modelings, such as oil production optimization (Badru and

35 Kabir , 2003, Zangl et al. , 2006), water flooding (Guyaguler et al. , 2000, Haghighat Sefat et al. , 2014), gas flooding (Ampomah et al. , 2016), steam injection, Alkaline-Surfactant-Polymer flooding (Zerpa et al. , 2007), SAGD process (Fedutenko et al. , 2013a,b, Vanegas Prada and Cunha , 2008, Yang et al. , 2011), well locations (White and Royer , 2003), history matching (Goodwin , 2015, He et al. , 2016, Zubarev , 2009), etc. The DoE approaches create multiple computer experiments (realizations) for the problem by combining the levels for each parameter. These experiments are 
evaluated to compute the response factor. The created experiments and response factor are included in the statistical modeling to establish a relationship, which represents the proxy or surrogate model. Many DoE approaches have been used in various reservoir simulation studies to build the proxy models. The most common DoE approaches are fractional factorial design (Vanegas Prada and

${ }_{45}$ Cunha , 2008), central composite design (Yeten et al. , 2005), D-optimal design (Zerpa et al. , 2007), and Latin Hypercube Design (Zubarev , 2009). There are many successful examples of using the proxy models in the literature of reservoir studies, such as second-degree polynomial equation (Avansi , 2009, Hassani et al. , 2011, Fedutenko et al. , 2013b, White and Royer , 2003), kriging algorithm (Fedutenko et al. , 2013b, Osterloh , 2008, Zubarev , 2009), and artificial neural networks (Zangl et al. , 2006, Zubarev , 2009).

In this paper, the Design of Experiment and proxy modeling were combined for the optimization of oil recovery through the Gas-Assisted Gravity Drainage (GAGD) process in the heterogeneous main pay of Zubair formation in south Rumaila oil field. To implement the optimization process, a full compositional reservoir simulation was constructed to evaluate the reservoir performance through the $\mathrm{CO}_{2}$-GAGD flooding for 10 years of future reservoir prediction. Then, the proxy model optimization was conducted through manipulating the operational decision parameters that influence the $\mathrm{CO}_{2}$ flooding through the GAGD process through the Design of Experiments (DoE). More specifically, the Design of Experiments and Proxy Modeling were combined to create a simplified alternative approach (metamodel) to the compositional reservoir simulation for the optimization of the operational decision parameters affecting the GAGD process. Four proxy models were adopted and validated as metamodels for the compositional reservoir simulator: polynomial proxy model, Multivariate Additive Regression Splines, Fuzzy Logic-Genetic Algorithm, and Generalized Boosted Modeling. The cross-validation with variance calculations were then used to validate these four proxy models. To best of our knowledge, Fuzzy Logic-Genetic Algorithm and Generalized Additive Modeling approaches have never been used before as proxy models in the reservoir simulation studies, especially in the gas injection workflows.

To the best of our knowledge, the presented workflow of Design of Experiments and Proxy Metamodeling has never been adopted on a real field-scale evaluation of a Gravity Drainage-based CO2-EOR Process, especially by using the Fuzzy Logic-Genetic Algorithm and Generalized Boosted Modeling as proxy models.

\section{Gas-Assisted Gravity Drainage Process}

Natural segregation of reservoir fluids is effective to enhance the recovery of bypassed oil through the CO2-Assisted Gravity Drainage (GAGD) process by providing gravity-stable oil displacement. The Gas-Assisted Gravity Drainage (GAGD) process has been patented to improved oil recovery in secondary and tertiary modes for both immiscible and miscible gas flooding processes (Rao , 2012). The GAGD process concept states placing horizontal producers at the bottom of a payzone. Then, the gas is injected either immiscible or miscible in a gravity-stable mode through the vertical wells from the top of formation (Rao et al. , 2004). Due to the gravity segregation resulting from the distinct fluid densities at reservoir conditions, the injected gas accumulates at the top of payzone to 
80 formulate a gas cap providing gravity stable oil displacement that drains down towards horizontal producer(s) and then leading to better sweep efficiency and higher oil recovery. Particularly, the CO2 gas is preferred for injection because it attains high volumetric sweep efficiency with high microscopic displacement efficiency, especially in miscible injection mode. Additionally, the high volumetric sweep efficiency assures delaying CO2 breakthrough to the producer(s) (Rao , 2012). Delaying or eliminating the gas breakthrough results in diminishing concurrent gas-liquid flow, which then leads to increased gas injectivity and maintains the injection pressure.

\section{Field Description}

South Rumaila oil field was discovered in October 1953. It is located in southern Iraq about $50 \mathrm{~km}$ west of Basrah city and about $30 \mathrm{~km}$ to the west of the Zubair oil field (Al-Ansari , 1993). The field is about $100 \mathrm{~km}$ long with a depth more than $3 \mathrm{~km}$ below sea level and a width ranging between 12 to $14 \mathrm{~km}$. Dip angles on the flanks do not exceed $3^{\circ}$ degrees, whereas in the crest it is about $1^{o}$ degree. South Rumaila oil field is composed of many oil-producing reservoirs. Zubair is one of the oil reservoirs that is represented by the Late Berriasian-Albian cycle and its sediments, which belongs to the Lower Cretaceous age. The Zubair formation is rich in organic deposition and accumulation of sedimentary matter. The thickness of the Zubair formation ranges between 280-400 $\mathrm{m}$ with levels increasing towards north-east end of the field (Al-Obaidi , 2009). Based on sand to shale ratio, the Zubair formation encompasses five members. These members named from top to bottom are as follows: upper shale, upper sandstone, middle shale, lower sand, and lower shale. The upper sandstone member of the Zubair formation is the main pay zone of South Rumaila Oil Field (Mohammed et al. , 2010). Zubair formation does not contain any complex geological features such as faults or fractures (Al-Ansari , 1993).

South Rumaila field is divided into four sectors. Listed from north to south, the sectors are: Qurainat, Shamiya, Rumaila, and Janubia. The investigated area includes Rumaila sector and small parts from Shamiya and Janubia sectors. The choice of this area was made based on the availability of data and the ability to represent the largest part, where the production and injection operations are carried out, shown in Figure 1.

There are two types of boundary conditions encountered in the main pay reservoir, a no-flow boundary and an aquifer. The northern and southern most boundaries are assumed to be a no-flow region. This assumption was considered realistic because the balanced production and injection rates were adopted in the reservoir. Furthermore, the isobaric lines crossing the northern streamlines is perpendicular to these boundaries. Thus, the direction of flow is parallel to the northern and southern boundaries, as shown in Figure 1. The flow boundaries at the east and west flanks represent the natural water drive due to the infinite aquifer (Al-Mudhafer et al. , 2010). not initiated until the 1980s to maintain infinite active edge-aquifer support from west flank, which accumulates up to 20 times the influx from east one (Al-Mudhafer et al. , 2010, Kabir et al. , 2007). During field production history, 40 producers were opened to flow in the sector under study. The 


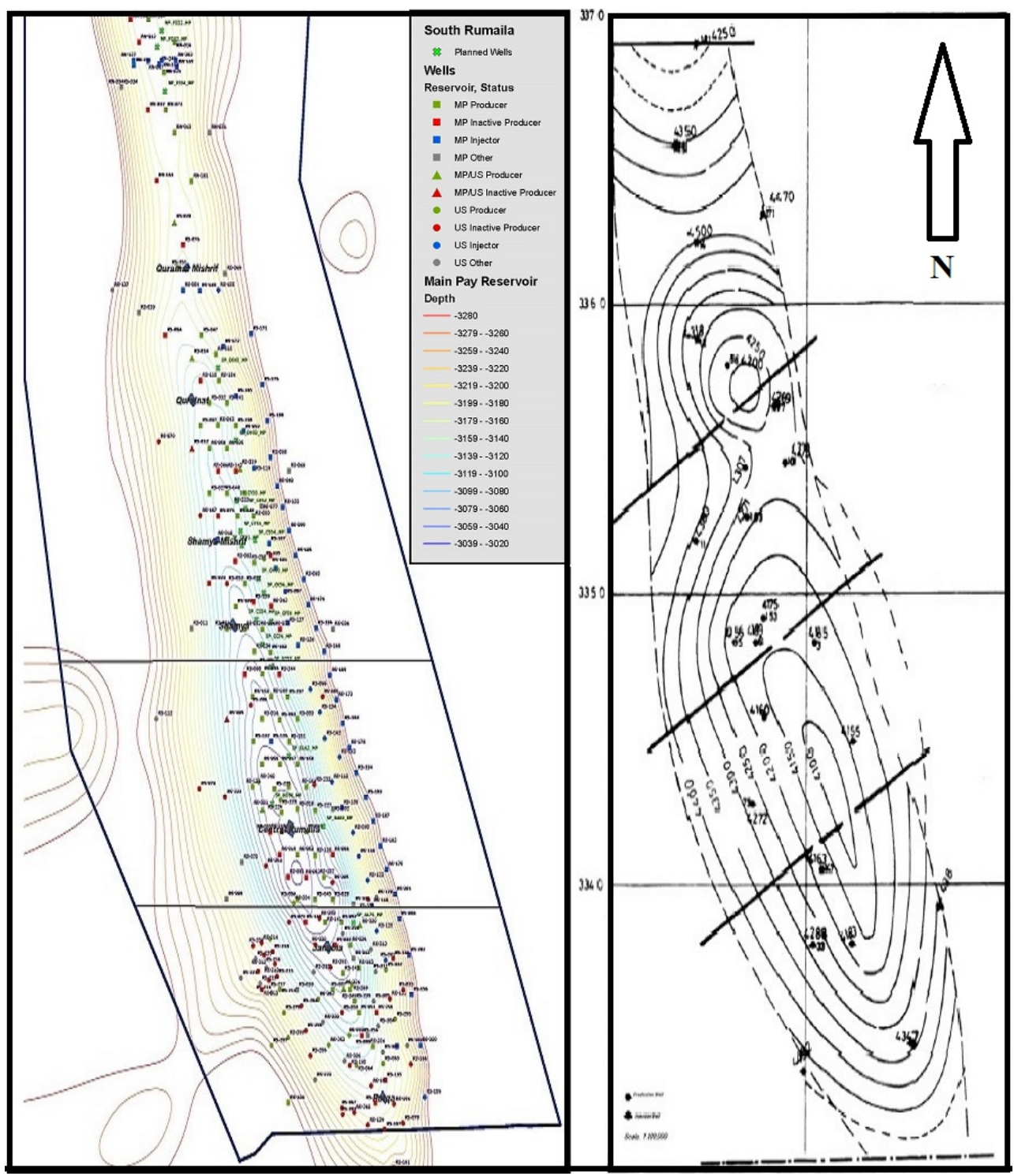

Figure 1: (Left) Sectors of the field with Well Locations. (Right) Isobaric Map of South Rumaila Oil Field, Modified from (Mohammed et al. , 2010)

production of some layers were ceased because the high water cut values exceeded $98 \%$. By the year 2004, the cumulative water injection was approximately 1.1 billion barrels. The injection rates have varied widely with a maximum of nearly 426,000 BPD for two months in 1988. Artificial lift has been recently installed in the main pay wells in order to handle the wells incapable of flowing to the surface after the water cuts reach approximately $80 \%$. The estimated original oil in place (OOIP) for the main pay is 19.5 billion barrels and for the sector is around 6.123 billions barrel. Moreover, the approximate current recovery factor is $55 \%$. The peak oil production was 1.35 MMBPD in May 1979. The current oil production in July 2013 was approximately 1.25 MMBPD.

\section{GAGD Process Simulation}

The main pay reservoir in the South Rumaila oil field was selected for a full detailed compositional reservoir simulation to enhance the recovery of bypassed oil through the GAGD process. The main pay has only three lithology types, which are sand, shaly sand, and shale, with distinct 
areal permeability distributions. A high-resolution geostatistical reservoir model, with 1,908,900 grids of 210, 202, and 45 grids in I, J, and K directions, has been reconstructed for lithofacies and petrophysical properties using the Multiple-Point Geostatistics and Sequnetial Gaussian Simulation, respectively (Al-Mudhafar , 2016a).

The geostatistical reservoir model was then upscaled for the GAGD process flow simulation. The upscaled reservoir model, with 55,000 grids of 69, 66, 12 grid dimensions, was exported to build the compositional reservoir flow simulation, which was implemented using the CMG-GEM package (CMG , 2015). For future field development evaluation, an excellent history matching was obtained through trial and error process with respect to field cumulative oil production and water injection as well as fluid flow rates. The production and injection matching is a good indicator of reservoir and fluid behavior as it reflects the matching of water cut and saturation distributions. The entire production history for the simulation period in this study is approximately 56 years. The production and injection flow rates were available until February 2010. Therefore, the history matching was achieved from 1954 until 2010. Figure 2 shows the matching between field production rates and cumulative oil production. Additionally, Figure 3 depicts the matching between field injection rates and cumulative water injection.

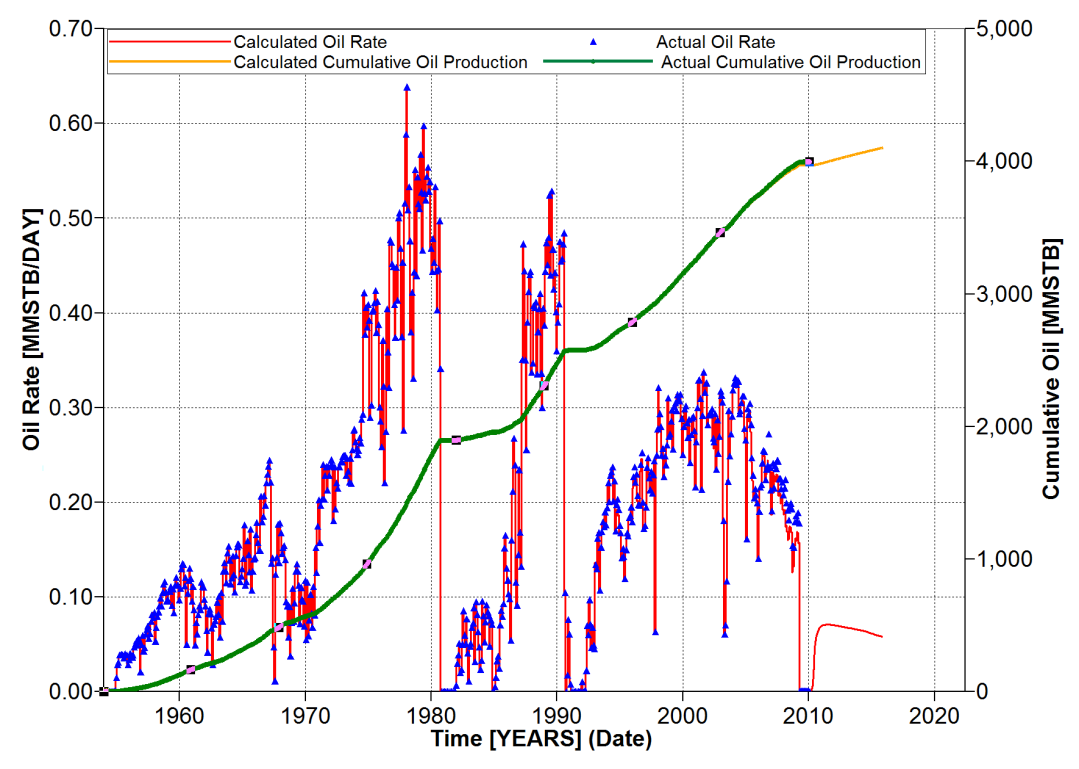

Figure 2: History Matching of Entire Field Production of South Rumaila Oil Field

To apply the main concept of the GAGD process, 22 vertical injection wells and a 11 horizontal producers with $3000 \mathrm{~m}$ length were placed through the reservoir at sand and shaly-sand lithology zones. Initially, $\mathrm{CO} 2$ is injected through the vertical injectors at the top two layers. At the same time, the 2nd three layers were left as a transition to allow a vertical depth interval for gas gravity drainage. Then, horizontal producers were set up through the sixth, seventh, and eighth layers where the oil saturation has the highest levels. Finally, the last four layers were left with no injection/production activity, as they are fully flooded with water from the infinite edge water aquifer. The total prediction period of CO2-GAGD process evaluation was set for 10 years (2016-2026). Figure 4 shows the locations of injection and production wells that are installed for CO2 flooding 


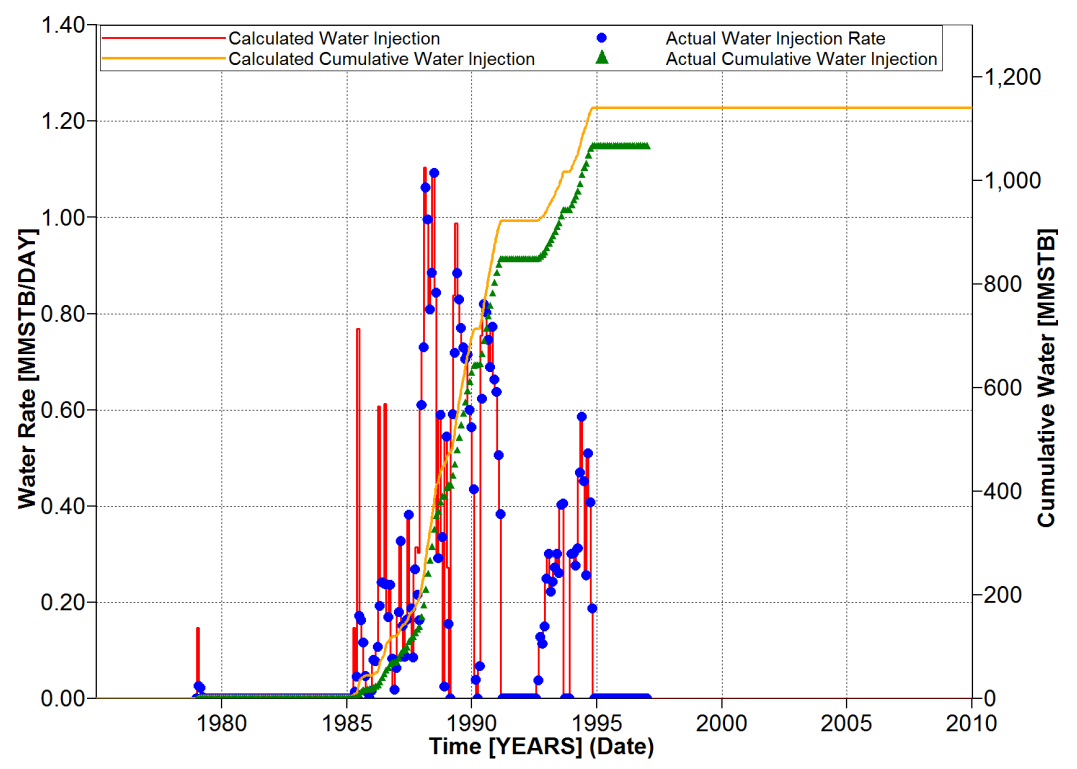

Figure 3: History Matching of Entire Field Injection of South Rumaila Oil Field

in the Gas Assisted Gravity Drainage process. In Figure 4, the reservoir body is represented by the red color, which denotes to shale zones. However, the perforations of producers and injectors were mainly placed in sand zones (indicator number 2), which have high permeability ranges, as well as shaly-sand zones (indicator number 1).

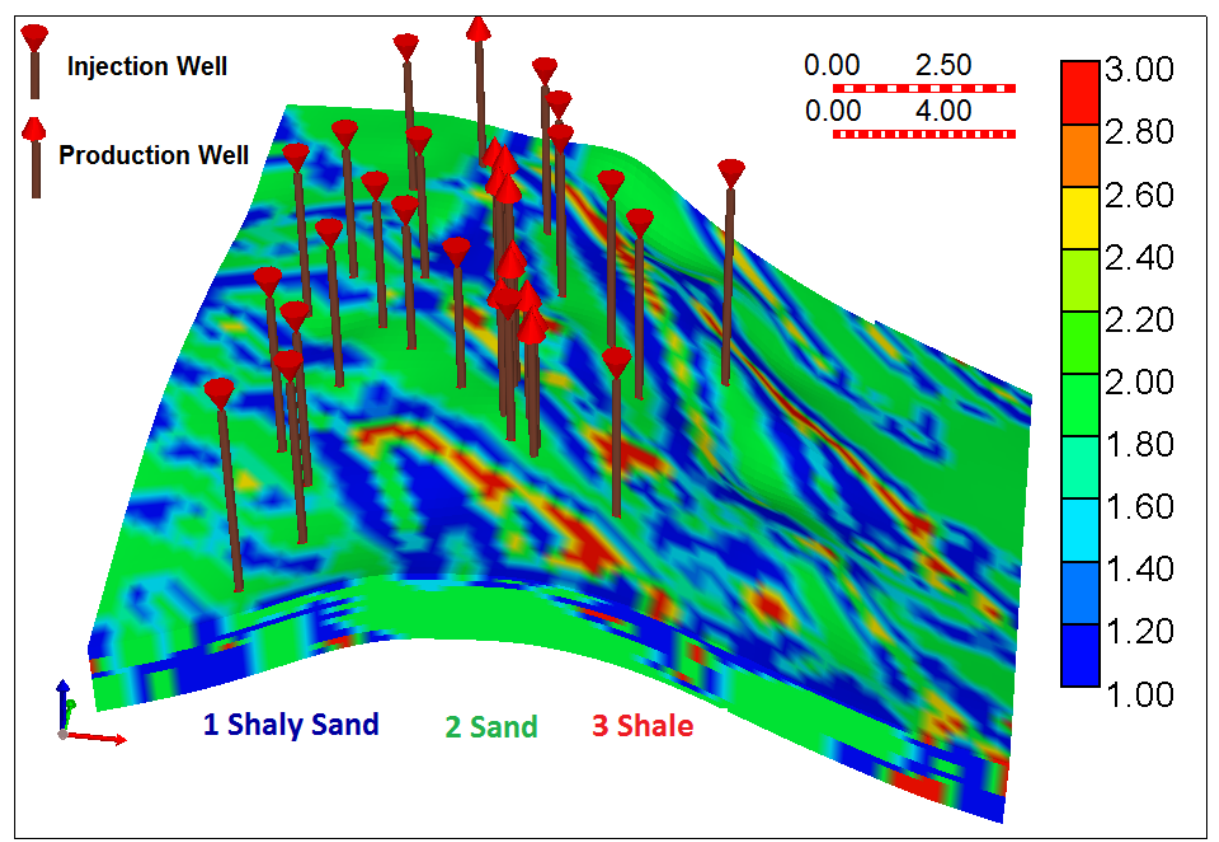

Figure 4: Production and Injection Well Locations in Sand and Shaly-Sand Zones

\section{Optimization Approaches}

The Design of Experiments (DoE) is a systematic statistical tool that creates a proper set of experiments for simulation. DoE is used for the purpose of identifying the most sensitive factors that affect the response through the sensitivity analysis procedure. Furthermore, DoE helps an 
individual to obtain the most-likely scenario that achieves the optimal response through a process (Lazic , 2006). The DoE has been proven as an efficient tool in conducting uncertainty framing, screening parameters, Bayesian updating of parameters, and risk analysis (Amudo et al. , 2009). Since the designed experiments are typically faster, cheaper and more flexible than physical or lab experiments, it is necessary to attain the most accurate model that mimics the physical model or process. To achieve that, the required numbers of factors and interactions should be analyzed to make the interpretation and application of results correct and reliable (White and Royer , 2003).

The main terminologies in Design of Experiments are response variable that simply represents the outcome from an experiment or process and factors, which are variable that affect the response variable. The values that a factor can assume are called levels. Primary and secondary factors are the variables that are more and less sensitive, respectively. The total number of designed experiments has an exponential formula. For instance, the number of experiments given $k$ variables with 3 levels equal $3^{k}$. The sampling techniques, such as factorial design, one factor at a time, and Latin Hypercube Sampling, should be considered to combine multiple levels for each factor in a systematic procedure to create a population of observations (Montgomery and Runger , 2003).

The Design of Experiments (DoE), Latin Hypercube Sampling, was adopted in this study with the proxy modeling to determine the optimal values of the operational production decision factors for the Gas-Assisted Gravity Drainage (GAGD) process optimization.

Latin Hypercube Sampling (LHS) is a statistical sampling tool that is used to create samples from the input factors in order to construct many computer experiments from a multidimensional distribution (McKay et al. , 1979). In order to capture many levels of variation for each factor with minimum experiments, the sampling techniques provide limited data points through the design domain in a uniform distribution through the space-filling design (Bhat, 2001). The Latin Hypercube sampling is one of these efficient designs that produces uniform and low discrepancy observations (McKay et al. , 1979). Figure 5 shows the space-filling design by LHS for two variables. In this figure, the sampled data are allocated within the entire space randomly. All the points are uniformly distributed to capture the entire variation of the process being studied, and that is the strength of Latin Hypercube Sampling approach.

Latin Hypercube sampling generates more efficient experiments for $\mathrm{K}$ parameters than simple Monte Carlo sampling. More specifically, LHS provides a regular spread points design because it keeps the maximum distance between each design point to all the other points (Stocki , 2005). Sampling $\mathrm{K}$ variables in LHS is performed by dividing each factor into many equal partitions. LHS is also an augmentation procedure that generates a new set of experiments in random manner if the original dataset does not represent the problem. There is no exact procedure to determine the number of experiments that can be created (Stein , 1987).

The computer experiments, which were generated for optimization, were accomplished in $\mathrm{R}$ statistical language by $[l h s]$ package (Carnell , 2015). 




Figure 5: Latin Hypercube Sampling Design given Two Variables(R output)

\section{Proxy Modeling}

The proxy approach deals with building a simplified model alternative to the complex model (metamodel). This proxy model enables users to obtain results similar to those gained by the complex model, but in much less computational time, in the order of a few seconds for millions of runs. However, the complex model consumes several days to obtain the results of hundreds runs. The proxy model is formulated by fitting the training dataset of the operational parameters, to the response factor, as illustrated in the following equation:

$$
y=f\left(X_{1}, X_{2}, \ldots, X_{k}\right)+\epsilon_{i}
$$

where $X_{1}, X_{2}, \ldots, X_{k}$ are the input variables and $y$ is the expected response factor.

Cross-validation is required to increase the chance of reaching global optima and to improve the prediction accuracy of the proxy model. The random sampling cross-validation is adopted on the entire experiments by sampling and splitting the dataset into two subsets: $70 \%$ training subset for modeling and 30\% testing subset for prediction (Al-Mudhafar , 2016c). More specifically, the training subset was considered for the modeling of cumulative oil production, obtained by the reservoir simulator, as a function of operational parameters. The prediction is then adopted as a function of the testing subset by the simulator as well as the proxy model.

In this paper, the comparison between the proxy models was conducted for the mismatch between the cumulative oil production calculated by the reservoir simulator and by the proxy model based on the testing subset, not the same training data. That cross-validation procedure ensures making external prediction from the same dataset (the results can be trusted when applied on external dataset). The mismatch was quantified by computing the Root Mean Square Prediction Error (RMSE) and the adjusted $R_{a d j}^{2}$. RMSE measures the expected squared difference between the simulator- and proxy-based response factor, cumulative oil production. While, the adjusted $R_{a d j}^{2}$ is a modified version of R-squared, which shows how much variance can be explained by a model. However, the adjusted $R_{a d j}^{2}$ is adjusted for the number of predictors in the model and it increases 
only if the new term improves the model.

$$
\begin{aligned}
R M S E & =\sqrt{\frac{1}{n} \sum_{j=1}^{n}\left(\hat{f}_{j}\left(x_{i}\right)-f_{j}\left(x_{i}\right)\right)^{2}} \\
R_{a d j}^{2} & =1-\frac{\left(1-R^{2}\right)(n-1)}{n-k-1}
\end{aligned}
$$

205 tors).

The complete flowchart for Design of Experiments, Proxy model, and cross-validation was shown in Figure 6.

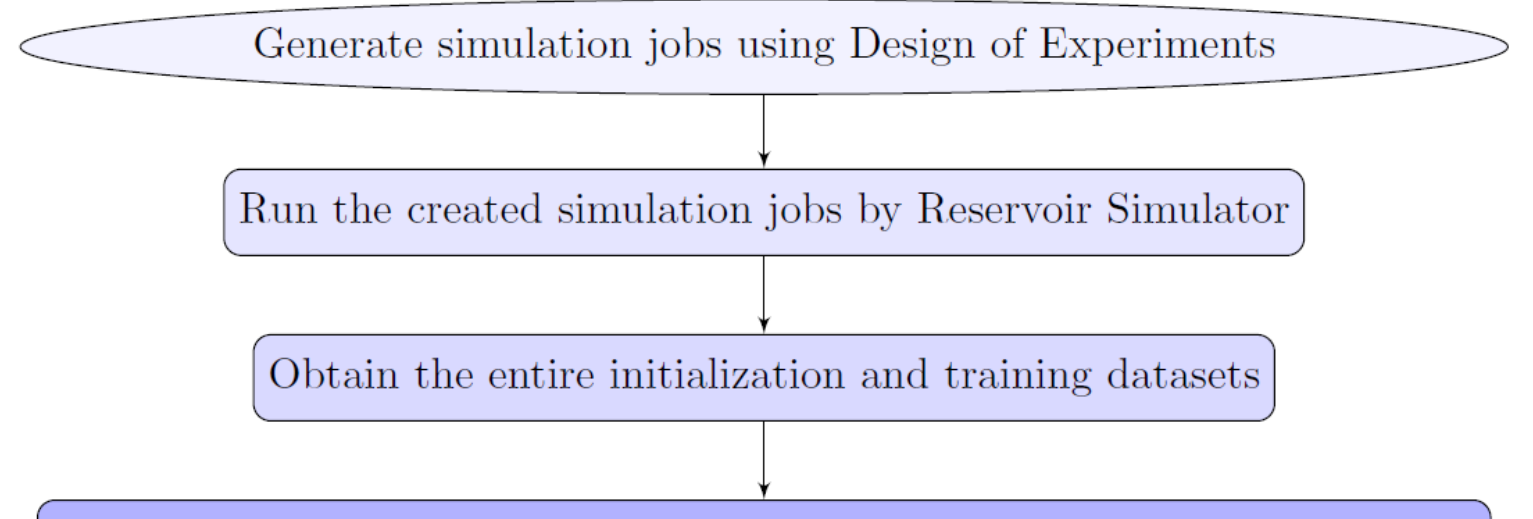

Cross-Validation: Dataset sample and split: $70 \%$ Training and 30\% Testing

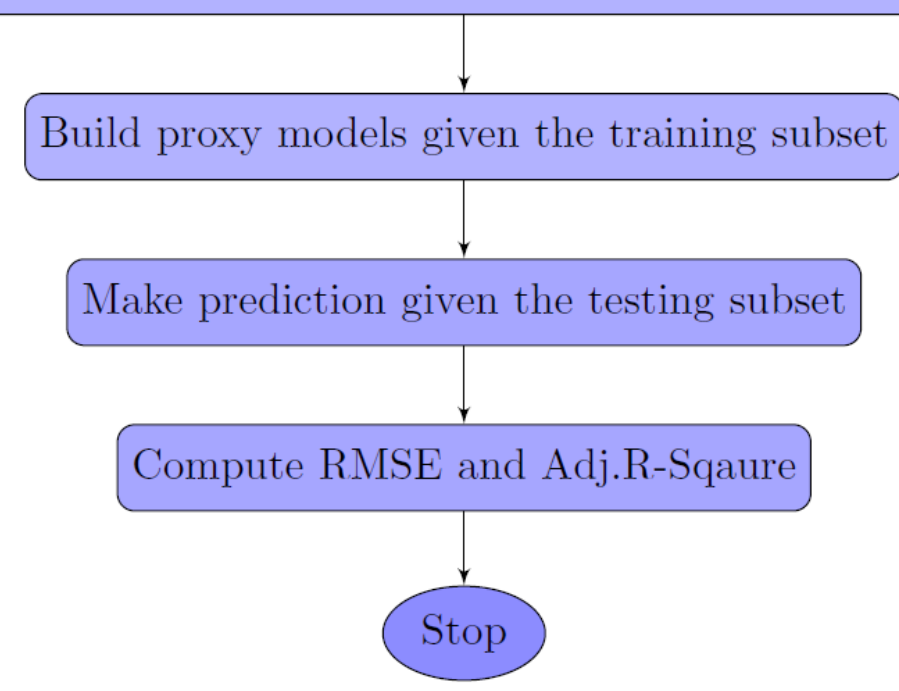

Figure 6: Flowchart of Design of Experiments-Proxy Optimization Algorithm

From the aforementioned Design of Experiments and proxy modeling, 643 simulation jobs (experiments of the operational parameters) were created for the training and validation runs. These runs were then adopted for the comparison of four proxy models: Polynomial (Quadratic) Regression (QM), Multivariate Additive Regression Splines (MARS), Fuzzy Log-Genetic Algorithm (FUzzyGEnetic), and Generalized Boosted Regression Model (GBM). 


\subsection{Polynomial Regression}

The Response Surface Methodology (RSM) is constructed by the 2nd degree polynomial (quadratic) regression that creates a nonlinear relationship between the response factor and the input variables (Zubarev , 2009, Fedutenko et al. , 2013a). The common model for the polynomial RSM is the second-degree quadratic model. For more than two parameters, it is represented by the following formula:

$$
y=\alpha_{0}+\sum_{j=1}^{k} \alpha_{j} X_{j}+\sum_{j=1}^{k} \alpha_{j j} X_{j}^{2}+\sum_{i<j} \sum_{j=2}^{k} \alpha_{i j} X_{i} X_{j}+\epsilon_{i}
$$

where $\alpha_{j}$ is the coefficient of linear term, $\alpha_{j j}$ is the coefficient of the quadratic terms, and $\alpha_{i j}$ is the coefficient of the interaction terms between every two variables. The response surface methodology was entirely implemented via R-statistical language by rsm package (Lenth , 2009).

\subsection{Multivariate Additive Regression Splines}

Multivariate Adaptive Regression Spines (MARS) is a nonparametric regression procedure that automatically fits the relationship between variables taking into account non-linearity using piecewise linear segments, called splines (Friedman , 1991). In MARS, a set of coefficients and basis functions, which are driven for the experiments data, are used to build the relationship between response parameter and predictors. MARS is suitable for high dimensional predictors because the basis functions partition the input data into regions, each with its own coefficients set in order to get rid of the possible outliers, which might be available in the dataset (Kooperberg, 2006).

The data modeling through MARS is performed by two main steps: forward phase that explores potential knots to improve the modeling performance, and backward procedure that eliminates the non-influential predictors (Adoko and Jiao , 2014). The MARS model is illustrated by the following equation that implements the forward step (Samui , 2013):

$$
y=c_{0}+\sum_{i=1}^{N} c_{i} \prod_{j=1}^{K_{i}} b_{j i}\left(X_{v(j, i)}\right)
$$

where:

$y$ : the output variable.

$c_{0}$ : constant.

$c_{i}$ : vector of coefficients of the non-constant basis functions.

$v(j, i)$ : the index of independent variables used in the $i^{\text {th }}$ term of the $j^{t h}$ product.

$b_{j i}\left(X_{v(j, i)}\right)$ : the truncated power basis function with $v(j, i)$.

$K_{i}$ : a parameter that limits the order of interactions.

$b_{j i}$ : the spline function.

Non-influential predictors are eliminated through the backward step according to the generalized cross-validation (GCV) criterion, which adaptively handles the different behaviors of data (Friedman , 1991). The entire implementation of MARS approach was performed through earth packages in the R-statistical language (Milborrow , 2016).

$$
G C V=\frac{1}{N} \sum_{i=1}^{N}\left[y_{i}-f\left(x_{i}\right)\right]^{2} /\left[\frac{N-(M+\delta(M-1) / 2}{N}\right]^{2}
$$




\subsection{Fuzzy Logic-Genetic Algorithm}

Fuzzy logic is a form of knowledge representation suitable for notions that cannot be defined precisely, but which depend upon their contexts. Fuzzy Logic is a convenient way to construct a fuzzy model of the input and output data. Fuzzy logic system consists of three stages: fuzzifier, fuzzy inference system, and defuzzifier (Al-Mudhafer and Alabbas , 2012). In particular. the mechanism of fuzzy logic system is as follows: in the fuzzifier stage, the crisp inputs to the system to form fuzzy inputs. The fuzzy inputs are then propagated into the inference system, where the actual computation is performed. The rule base, where the expert knowledge is contained, is combined with fuzzy inputs and the inference engine in order to produce fuzzy outputs for each rule. These fuzzy outputs form a fuzzy set, which is transformed into a crisp value by the defuzzifier stage (Hinterding et al. , 1997). However, Genetic Algorithm is a random search tool tp generate potential solutions compete with each other in order to find optimal solution by applying operators of selection, crossover (recombination), and mutation that mimics the genetic reproduction in biological sense similar to Darwin's theory of Natural Selection (Goldberg , 1989).

Fuzzy Logic-Genetic Algorithm (FUzzy-GEnetic) is an evolutionary algorithm of fuzzy systems population, which is randomly generated by Genetic Algorithm, to be used as a prediction model by fitting the given training data as labels. The full procedure of FUzzy-GEnetic proxy modeling was implemented through fugeR R-package (Bujard , 2015). In fugeR, all the fuzzy system are tested with the data. Their predictions are then compared with the labels and a "performance" is given at each system. The population of chromosomes is then used to generate a $20 \%$ population for the next generation using crossover and mutation. At the last generation, the fuzzy system that obtained the best performance is returned.

\subsection{Generalized Boosted Regression Model}

Gradient Boosting Regression Model (GBM) is a powerful machine-learning tool derived by Friedman $(2001,2002)$ to capture complex non-linear function dependencies. Specifically, Generalized Boosted Regression is an implementation of expansion to Freund and Schapire's AdaBoost algorithm and J. Friedman's gradient boosting machine (Freund and Schapire , 1997). GBM has been efficiently adopted in many data-driven tasks with high accuracy of modeling and prediction of response variables. In gradient boosting modeling, an accurate modeling is obtained through consecutively fitting new models in order to reduce the variance between the predicted and observed responses. The main idea of GBM is to learn the data to achieve maximum correlation with the negative gradient of the loss function (Natekinand Knoll , 2013). For continuous response, the lossfunction can be Gaussian or Laplace functions. However, binomial and Adaboost loss function are suitable for the categorical responses.

The idea behind loss functions in GBM is to penalize large deviations from the target outputs along with neglecting small residuals. For continuous response variable, the appropriate loss function is the squared-error L2 loss and its derivative represents the residual. So, the GBM can be applied based on the residual fitting (Natekinand Knoll , 2013). The GBM procedure begins with assigning a differentiable loss function and starts with an initial model $F$. Then, iteration is implemented 
until converge in order to next calculate negative gradients:

$$
-g\left(x_{i}\right)=-\frac{\partial L\left(y_{i}, F\left(x_{i}\right)\right)}{\partial F\left(x_{i}\right)} .
$$

The regression tree $h$ is later fitted to the negative gradients $-g\left(x_{i}\right)$. The full procedure of GBMbased proxy modeling was implemented by $\mathrm{gbm}$ package in $\mathrm{R}$, the most powerful open-source statistical language (Ridgeway , 2007).

\section{GAGD Production Optimization}

The six operational decision parameters investigated for the immiscible GAGD production optimization are: maximum oil production rates $\left(M A X_{-} S T O\right)$, minimum bottom hole pressure $\left(M I N \_B H P\right)$, water-cut $\left(M A X_{-} W C U T\right)$, and skin factor in production wells, along with maximum gas rate $\left(M A X_{-} B H G\right)$ and minimum bottom hole injection pressure $\left(M A X_{-} B H P\right)$ in injection wells. Table 1 illustrates the default values of the base case simulation of the GAGD process in addition to the ranges of each parameter (minimum and maximum levels) in the optimization process.

Table 1: Parameters of the GAGD Production Optimization

\begin{tabular}{r|rrr} 
Response & Min & Base Case & Max \\
CumOilProd, STB & $4.2208 \mathrm{E} 09$ & $4.3887 \mathrm{E} 09$ & $4.6039 \mathrm{E} 09$ \\
\hline Factor & Min & Base Case & Max \\
\hline MAX_STO, STB/DAY & 350000 & 750000 & 625000 \\
MIN_BHP, Psia & 2000 & 2660 & 3500 \\
MAX_WCUT & 0.70 & 0.95 & 0.90 \\
Skin Factor & 5 & 0 & 15 \\
MAX_BHG, ft ${ }^{3} / D A Y$ & $7.5 \mathrm{E} 06$ & $10 \mathrm{E} 06$ & $15 \mathrm{E} 06$ \\
MAX_BHP, Psia & 2000 & 3000 & 3500 \\
\hline
\end{tabular}

The levels of each factors in Table 1 were combined by the Latin Hypercube Sampling to produce hundreds of simulation jobs (experiments). Then, the designed experiments were evaluated through the compositional reservoir simulator to calculate the cumulative oil production by the end of 10 years prediction period (January 1, 2026). The optimal solution referred to the simulation job that results to obtain the maximum cumulative oil production, as illustrated in Figure 7 . It also demonstrates the field cumulative oil production through the base case of the GAGD process in addition to the general solutions that represent the non-optimal cases. The total number of the generated simulation jobs including the optimal solution was approximately 625 runs.

The optimal solution was identified and visualized with respect to the field cumulative oil production, as were outlines in Figure 8. The optimal solution represents the maximum field cumulative oil production by the end of the 10 years prediction period. The general solutions in Figure 8, represented by the green curves, refer to the least flow response that combine low and/or poor combinations of the factors' levels. Hence, they led to low levels of field cumulative oil production. 


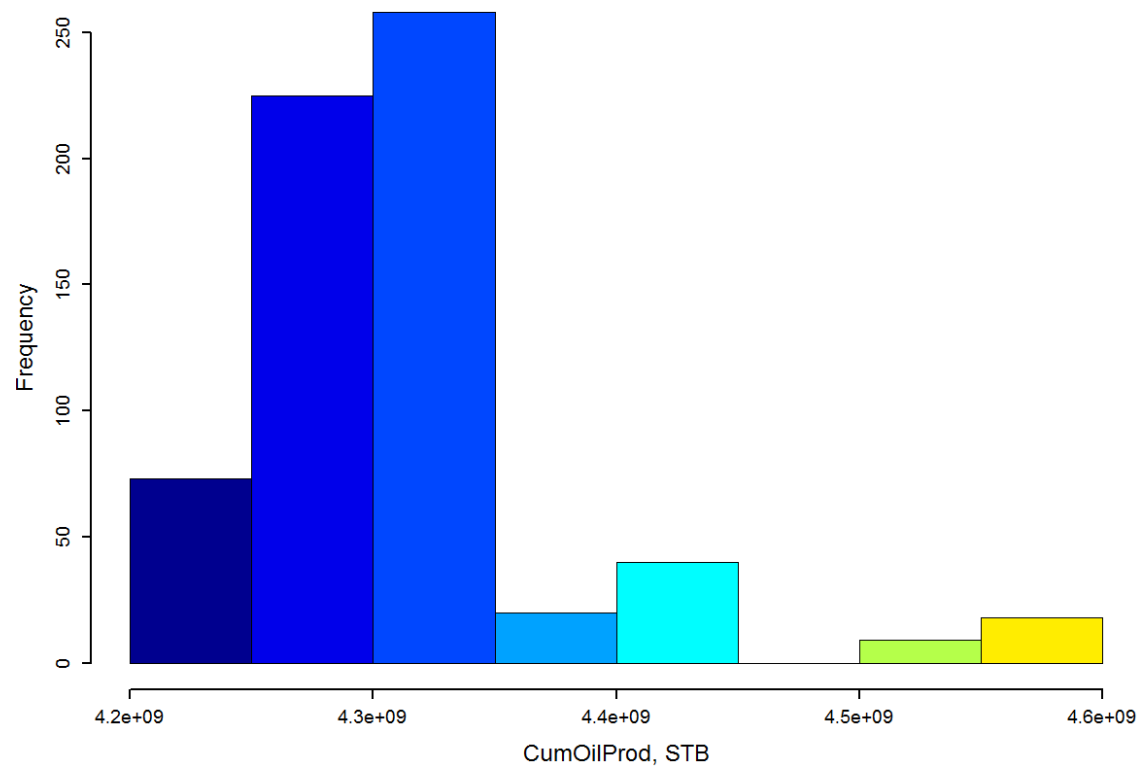

Figure 7: Histogram of the Base Case, General and Optimal Cumulative Oil Production through the Latin Hypercube Sampling-based GAGD Process Optimization

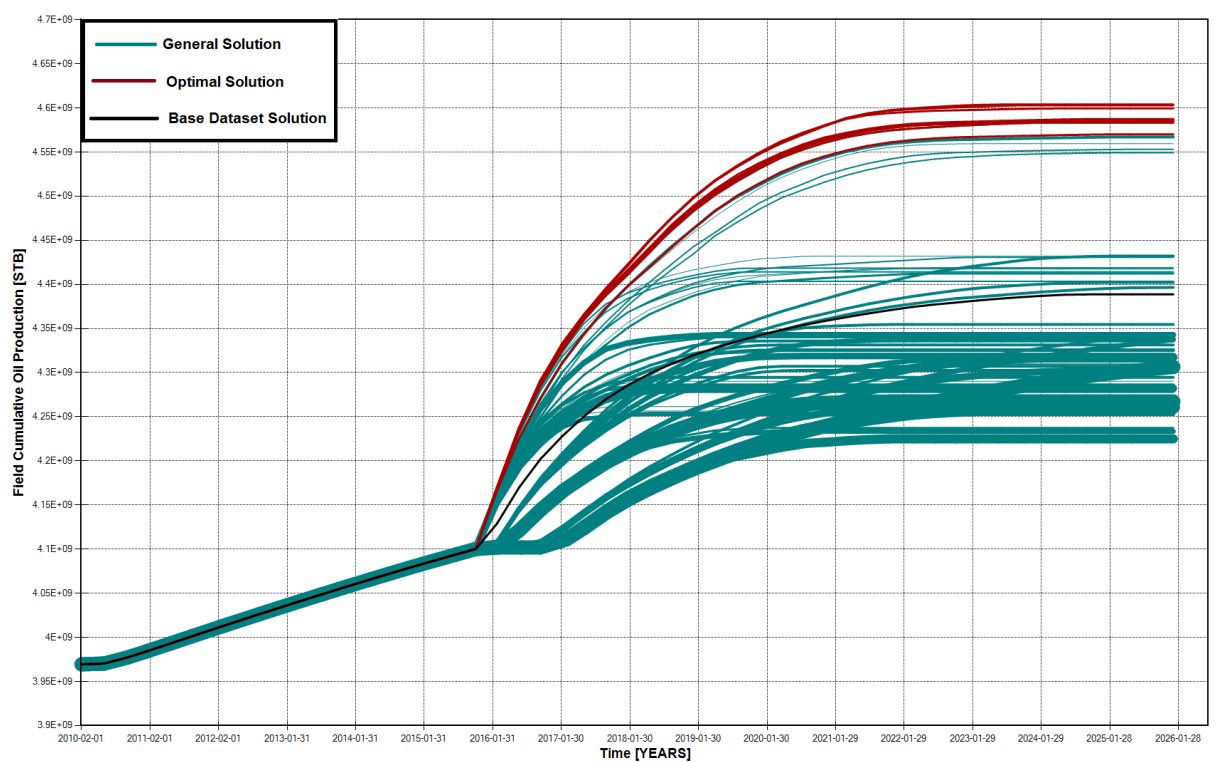

Figure 8: Base Case, General and Optimal Field Cumulative Oil Production through the LHS-based Proxy Optimization

The cumulative oil production by the end of the prediction period through base case-GAGD process was 4.3887 billion STB. However, the optimal solution, obtained from LHS-based proxy pptimization (OptimalCase), led to increase the cumulative oil production to 4.6039 billion STB. The incremental oil recovery is 215.2 million STB, as illustrated in Figure 9, which compares the base case and optimal GAGD process performance along with the primary production case of no injection. The optimal cumulative oil production was acquired by obtaining the optimal levels of all the production control factors, which are illustrated in Table 2 . 


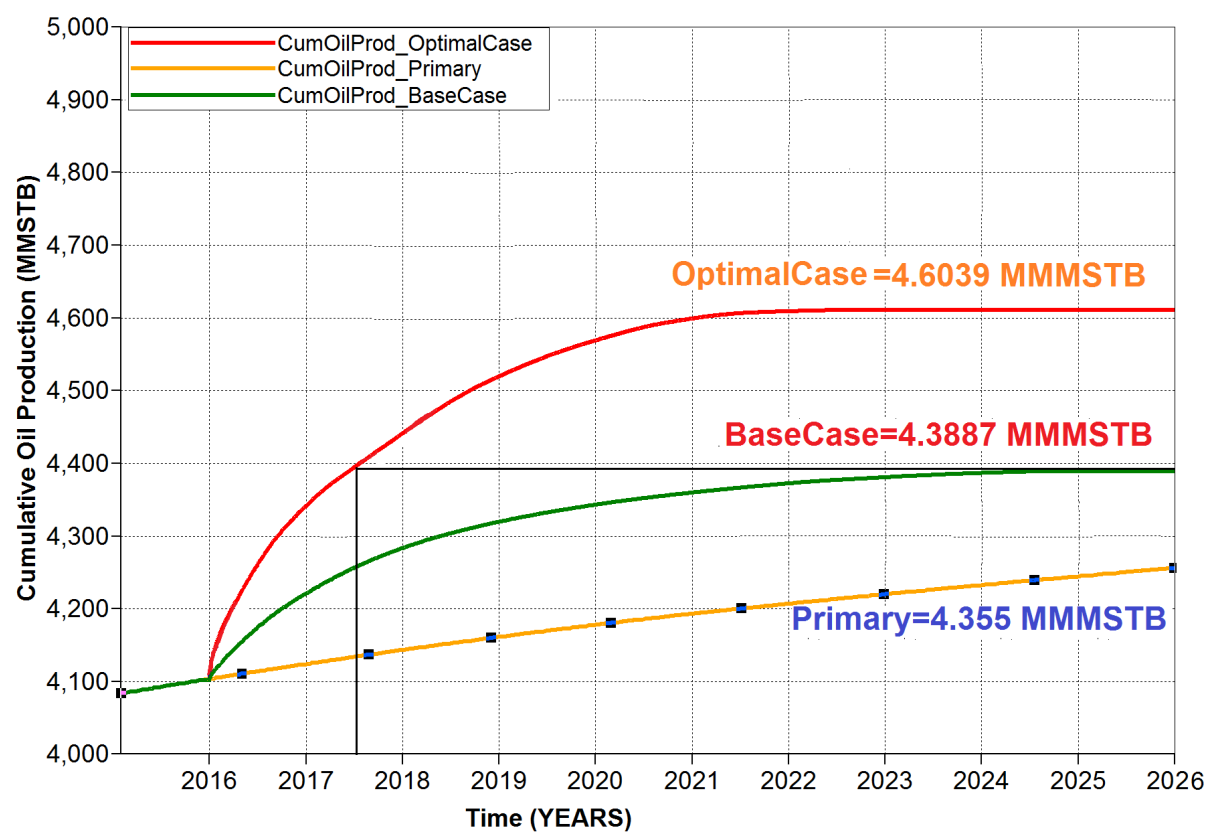

Figure 9: Comparison of Oil Production between Primary, Base, and Optimal Cases

In Figure 9, there is significant increment in oil recovery obtained from the optimal solution in comparison with the base case of default setting of the operational decision factors. The field cumulative oil production obtained by the base case in 10 years can be produced after only 18 months within the prediction period.

Table 2: Optimal Levels of the Operational Decision Factors in Comparison with the Base Case

\begin{tabular}{|c|c|c|}
\hline Response & Base Case & Optimal \\
\hline CumOilProd, STB & 4.3887E09 & 4.6039E09 \\
\hline Factor & Base Case & Optimal \\
\hline MAX_STO, STB/DAY & 750000 & 500000 \\
\hline MIN_BHP, Psia & 2660 & 2000 \\
\hline MAX_WCUT & 0.95 & 0.9 \\
\hline Skin Factor & 0 & 5 \\
\hline MAX_BHG,$f t^{3} / D A Y$ & $10 \mathrm{E} 06$ & $15 \mathrm{E} 06$ \\
\hline MAX_BHP, Psia & 3000 & 3500 \\
\hline
\end{tabular}

\subsection{Validation of the Proxy Models}

The entire procedure of proxy based optimization was illustrated considering the iterative procedure of constructing a polynomial model. The 643 simulation jobs were then used for a comparison of building new proxy models through four various approaches in a different procedure. The new four proxy metamodels are Polynomial (Quadratic) Regression (QM), Multivariate Additive Regression Splines (MARS), Fuzzy Logic-Genetic Algorithm (FUzzy-GEnetic), and Generalized Boosted Model (GBM). This procedure integrates cross-validation with Root Mean Square Error and adjusted $R^{2}$ to 
find the optimal proxy model that can be considered as a perfect metamodel for the nonlinear CO2GAGD process.

After sampling and subdividing the dataset of 643 designed experiments into $75 \%$ training and $25 \%$ testing subsets, the modeling was implemented based on 480 simulation jobs (training subset) through the four aforementioned proxy approaches. The prediction from each of the four proxy models was then adopted based on 163 runs (testing subset). The Root Mean Square Error (RMSE) and the adjusted $R^{2}$ were then computed to compare between the calculated cumulative oil production from the reservoir simulator and the predicted from the proxy model. Figures 10, 11, 12, and 13 illuminates the matching between the calculated cumulative oil production from the simulator (Observed) and the predicted from the proxy models (Predicted) with respect to the jobs for the QM, MARS, FUzzy-GEnetic, and GBM, respectively. In the (Left) figures, the blue balls refer to the observed response values, cumulative oil production calculated from the compositional reservoir simulator. However, the red balls represent the predicted cumulative oil production from the four proxy models. In addition, the (Right) figures represent the scatter plots of matching between simulator- and proxy-based cumulative oil production.
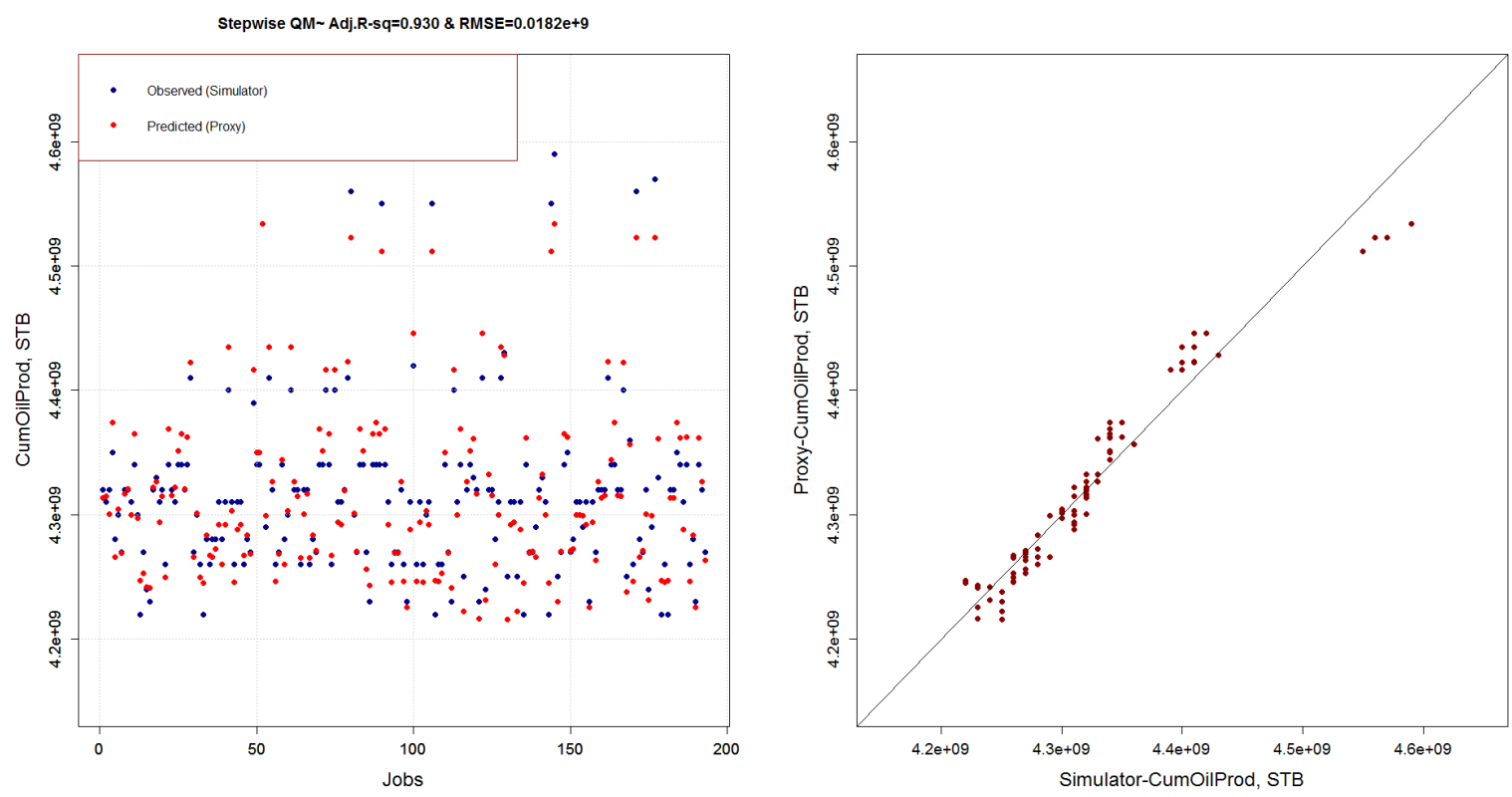

Figure 10: Comparison of Proxy-Predicted and Simulator Calculated-QM 

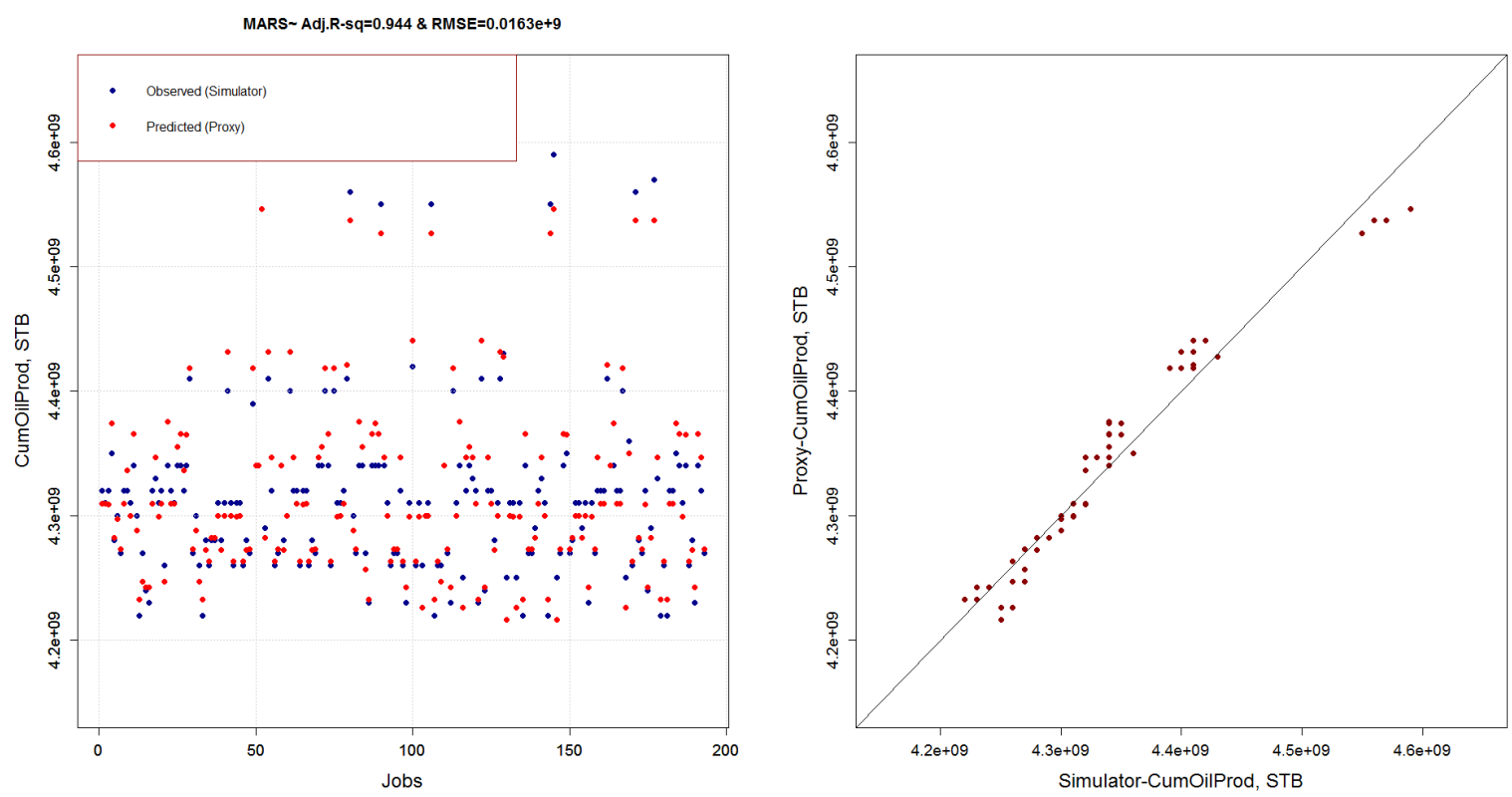

Figure 11: Comparison of Proxy-Predicted and Simulator Calculated-MARS
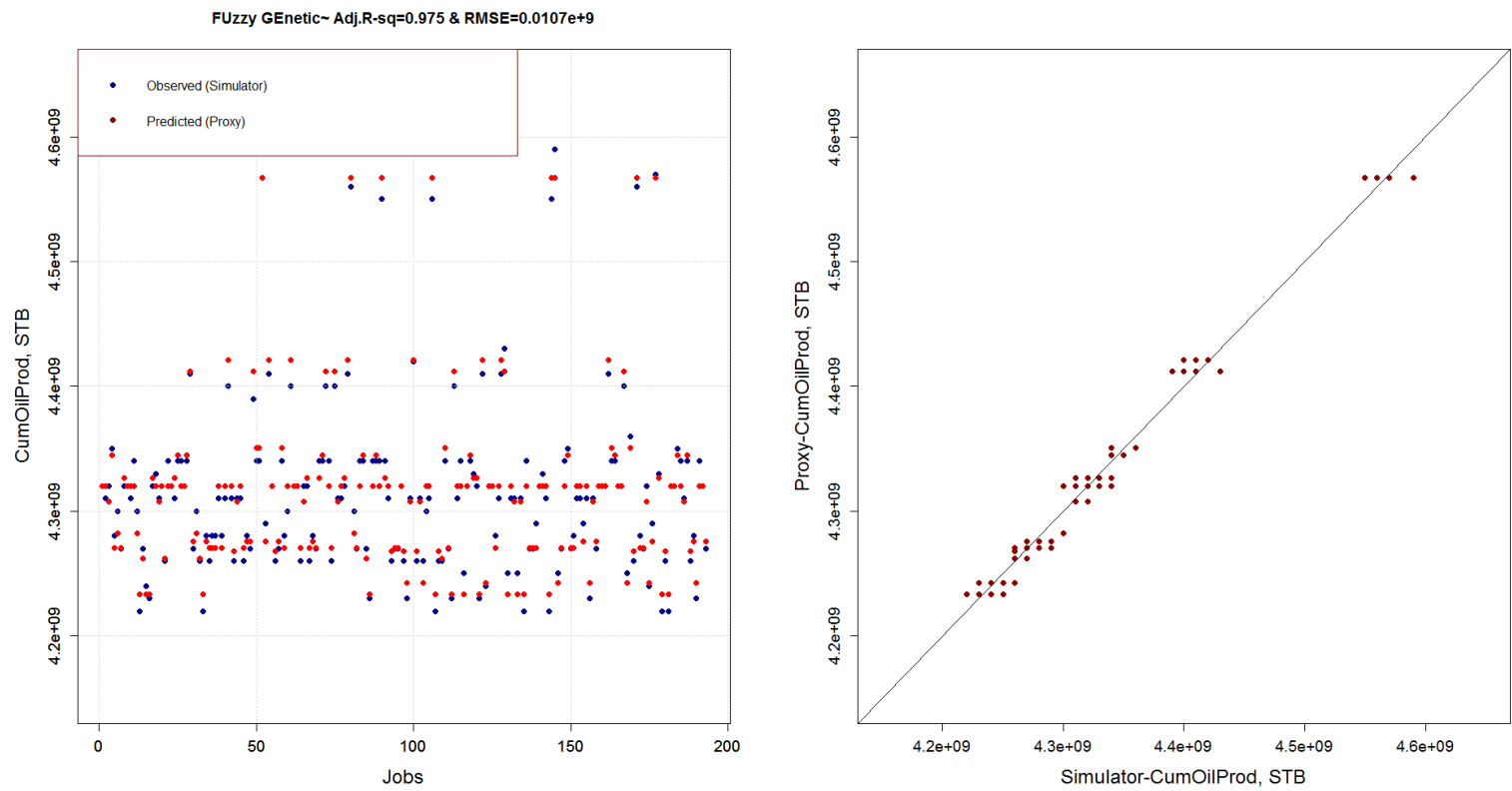

Figure 12: Comparison of Proxy-Predicted and Simulator Calculated-FUzzy-GEnetic 

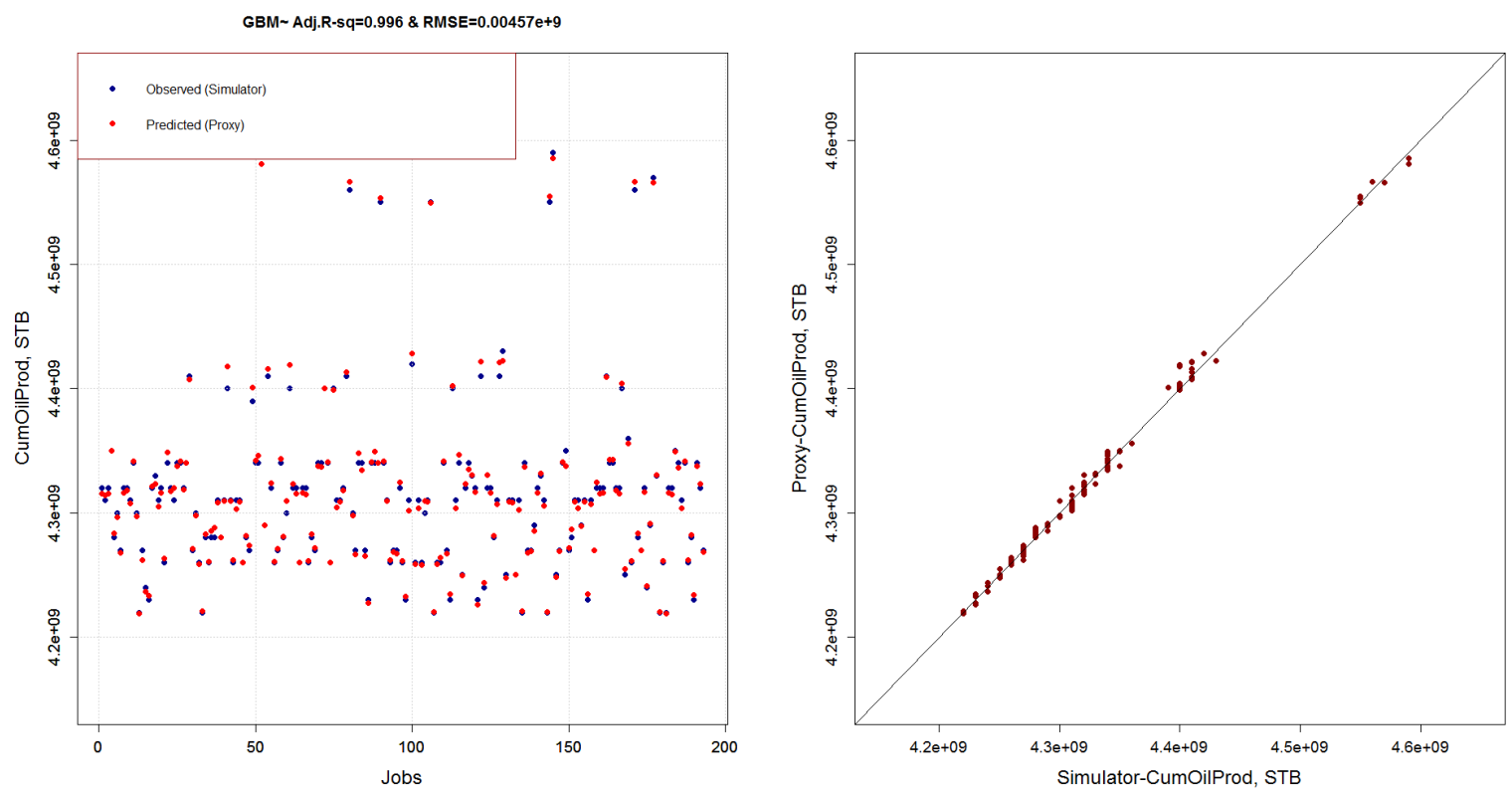

Figure 13: Comparison of Proxy-Predicted and Simulator Calculated-GBM

The RMSE values for the QM, MARS, FUzzy-GEnetic, and GBM are 0.0182e+9, 0.0163e+9, $0.0107 \mathrm{e}+9$, and $0.00457 \mathrm{e}+9$, respectively. While, the values of $R_{a d j}^{2}$ were $0.930,0.944,0.975$, and 0.996, respectively. The GBM and FUzzy-GEnetic proxy models are better than the QM and MARS as they have the best values RMSE and $R_{a d j}^{2}$. Moreover, the scatter matching between the simulatorand proxy-based cumulative oil production from the GBM and FUzzy-GEnetic proxy models are better than QM and MARS models as all the points fit the $45^{0}$ degree line.

\section{Summary and Conclusions}

The compositional reservoir simulator was conducted for the Gas-Assisted Gravity Drainage (GAGD) process simulation in the heterogeneous main pay of Zubair formation in South Rumaila oil field. After achieving history matching, 10 years of future production was set as a prediction period to obtain the optimal oil recovery through manipulating the values of the operational decision factors that control the production and injection activities. The Latin Hypercube Sampling was adopted as a low-discrepancy Experimental Design approach to generate hundreds of experiments to be evaluated by the reservoir simulator in order to find the optimal oil recovery and build the proxy model.

That Design of Experiments and proxy modeling approach includes determining the optimal set of operational decision parameters through immiscible GAGD process. The parameters are CO2 injection rate and maximum BHP in the injection wells, along with the maximum oil production rate, minimum BHP, skin factor, and maximum water cut in the horizontal producers. This optimal case led to obtain 4.6039 million STB with increment of 212.5 million STB of oil over the base GAGD case (360 million STB over the primary production case).

The first proxy modeling workflow includes generate simulation jobs as training runs to build 
the proxy model, which was iteratively validated through four sets of validation tests (verification runs). In order to create an accurate proxy model that truly models the composition reservoir simulator (metamodel), the polynomial regression in addition to three more approaches were used to constructed the proxy models. The four models are Polynomial (Quadratic) Regression (QM), Multivariate Additive Regression Splines (MARS), Fuzzy Logic-Genetic Algorithm (FUzzy-GEnetic), and Generalized Boosted Model (GBM). It was noticed that the GBM model was the most accurate metamodel for the GAGD process as it achieve the lowest RMSE and the highest adjused $R_{a d j}^{2}$ that both reflect the least mismatch between the cumulative oil production calculated by the reservoir simulator and predicted by the GBM-proxy models. In addition, the FUzzy-GEnetic proxy models was the second best matching model. While, the polynomial and MARS proxy model led to obtain the highest RMSE and the lowest $R_{a d j}^{2}$ as there was significant mismatch between the cumulative oil production calculated by the simulator and predicted by the two proxy models. Additionally, the simulator- and proxy-based cumulative oil production from the GBM and FUzzy-GEnetic proxy models have better scatter points matching than the QM and MARS. Consequently, each of GBM and FUzzy-GEnetic can be adopted as a simplified alternative metamodel to the full resolution compositional reservoir simulator through the GAGD Process evaluation and prediction.

\section{Abbreviations}

- CGI: Continuous Gas Injection

- DoE: Design of Experiments

- EOR: Enhanced oil recovery

- FUzzy-GEnetic: Fuzzy Log-Genetic Algorithm

- GAGD: Gas-Assisted Gravity Drainage

- GBM: Generalized Boosted Regression Model

- GCV: Generalized cross-validation

- LHS: Latin Hypercube Sampling

- MARS: Multivariate Additive Regression Splines

- $M A X_{-} B H G$ : Maximum gas injection rate

- $M A X_{-} B H P$ : Minimum bottom hole pressure

- MAX_STO: Maximum oil production rates

- $M A X_{-} W C U T$ : Maximum water-cut

- MIN_BHP: Minimum bottom hole injection pressure

- QM: Polynomial (Quadratic) Regression 
- $R^{2}$ : Coefficient of Correlation

- $R_{a d j}^{2}$ : Adjusted Coefficient of Correlation

- RMSE: Root Mean Square Prediction Error

- WAG: Water-Alternating-Gas

\section{Acknowledgments}

The authors thank Fulbright-Institute of International Education (IIE) for 3-years PhD scholarship along with software support from Computer Modeling Group.

Adoko, A. C., Jiao, Y. Y. Predicting Tunnel Convergence in Weak Rocks: Multivariate Adaptive Regression Spline and Rough Set Theory Approaches. ISRM International Symposium-8th Asian Rock Mechanics Symposium, (14-16 October), Sapporo, Japan (2014).

Al-Ansari, R. The petroleum Geology of the Upper sandstone Member of the Zubair Formation in the Rumaila South. Geological Study, Ministry of Oil, Baghdad, Iraq (1993).

Al-Mudhafar, W. Multiple-Point Geostatistical Lithofacies Simulation of Fluvial Sand-Rich Depositional Environment: A Case Study from Zubair Formation/ South Rumaila Oil Field. Offshore Technology Conference, (2-5 May), Houston, TX, USA (2016). http://dx.doi.org/10.4043/ 27273-MS.

Al-Mudhafar, W. Incorporation of Bootstrapping and Cross-Validation for Efficient Multivariate Facies and Petrophysical Modeling. SPE Low Perm Symposium, (5-6 May), Denver, Colorado, USA (2016). https://doi.org/10.2118/180277-MS.

Al-Mudhafer, W. J. M., Alabbas, M. Application of a Hybrid System of Genetic Algorithm \& Fuzzy Logic as Optimization Techniques for Improving Oil Recovery in a Sandstone Reservoir in Iraq. SPE-149982-MS, presented at the SPE Latin America and Caribbean Petroleum Engineering Conference, (16-18 April), Mexico City, Mexico (2012). http://dx.doi.org/10.2118/149982-MS.

Al-Mudhafer, W. J., Al Jawad, M. S. and D. A. Al-Shamaa. Using Optimization Techniques for Determining Optimal Locations of Additional Oil Wells in South Rumaila Oil Field. CPS/SPE International Oil and Gas Conference and Exhibition, Beijing, China (2010). http://dx.doi. org/10.2118/130054-MS.

Al-Obaidi, R.Y. Identification of Palynozones and Age Evaluation of Zubair Formation, Southern Iraq. Journal of Al-Nahrain University, 12(3): 16-22 (2009).

Ampomah, W., Balch, R. S., Grigg, R. B., Cather, M., Will, R. A., Lee, S. Y. Optimization of CO2-EOR Process in Partially Depleted Oil Reservoirs. SPE Western Regional Meeting, (23-26 
Amudo, C., T. Graf, R. R. Dandekar, and J. M. Randle. The Pains and Gains of Experimental Design and Response Surface Applications in Reservoir Simulation Studies. SPE Reservoir Simulation Symposium, (2-4 February), Houston, Texas (2009). http://dx.doi.org/10.2118/118709-MS.

Avansi, G. D. Use of Proxy Models in the Selection of Production Strategy and Economic Evaluation of Petroleum Fields. SPE Annual Technical Conference and Exhibition, (4-7 October), New Orleans, Louisiana (2009). http://dx.doi.org/10.2118/129512-STU.

Badru, O., Kabir, C. S. Well Placement Optimization in Field Development. SPE Annual Technical Conference and Exhibition, (5-8 October), Denver, Colorado (2003). http://dx.doi.org/10. 2118/84191-MS.

Bhat, C. R. Quasi-Random Maximum Simulated Likelihood Estimation of the Mixed Multinomial Logit Model. Transportation Research Part B: Methodological, (35)7, 677-693 (2001). http: //dx.doi.org/10.1016/S0191-2615(00)00014-X.

Bujard, A. Package 'fugeR': FUzzy GEnetic, a machine learning algorithm to construct prediction model based on fuzzy logic. https://cran.r-project.org/web/packages/fugeR/fugeR.pdf.

Carnell, R. Package 'lhs'. (2015). Available at: https://cran.r-project.org/web/packages/lhs/ lhs.pdf.

CMG. The Computer Modeling Group's Reservoir Simulation Manual, Calgary, AB, Canada (2015).

Fedutenko, E., Yang, C., Card, C. Naghiem, L. Optimization of SAGD Process Accounting for Geological Uncertainties Using Proxy Models. CSPG/CSEG/CWLS GeoConvention, Calgary, AB, Canada (2013).

Fedutenko, E., Yang, C., Card, C. Naghiem, L. Time-Dependent Proxy Modeling of SAGD Process. SPE Heavy Oil Conference-Canada, Calgary, AB, Canada (2013). http://dx.doi.org/10.2118/ 165395-MS.

Freund, Y. and R. E. Schapire. A decision-theoretic generalization of online learning and an application to boosting. Journal of Computer and System Sciences, 55(1): 119-139 (1997). http://dx.doi.org/10.1006/jcss.1997.1504

Friedman, J. H. Multivariate adaptive regression splines. The annals of statistics, 1-67 (1991).

Friedman, J.H. Greedy Function Approximation: A Gradient Boosting Machine. Annals of Statistics 29(5): 1189-1232 (2001). http://www.jstor.org/stable/2699986.

Friedman, J.H. Stochastic Gradient Boosting. Computational Statistics and Data Analysis 38(4): 367-378 (2002). http://dx.doi.org/10.1016/S0167-9473(01)00065-2.

Goldberg, D. E. Genetic Algorithm in Search, optimization and Machine learning. Addison-Wesley, Reading, MA (1989). 
Goodwin, N. Bridging the Gap Between Deterministic and Probabilistic Uncertainty Quantification Using Advanced Proxy Based Methods. SPE Reservoir Simulation Symposium, (23-25 February), Houston, Texas (2015). http://dx.doi.org/10.2118/173301-MS.

Guyaguler, B., Horne, R. N., Rogers, L., Rosenzweig, J. J. Optimization of Well Placement in a Gulf of Mexico Waterflooding Project. SPE Annual Technical Conference and Exhibition, (1-4 October), Dallas, Texas (2000). http://dx.doi.org/10.2118/63221-MS.

Haghighat Sefat, M. Salahshoor, K., Jamialahmadi, M., Vahdani, H. The Development of Techniques for the Optimization of Water-flooding Processes in Petroleum Reservoirs Using a Genetic Algorithm and Surrogate Modeling Approach. Energy Sources, Part A: Recovery, Utilization, and Environmental Effects,36(11): 1175-1185 (2014). http://dx.doi.org/10.1080/15567036.2010. 538803.

Hassani, H., Sarkheil, H., Foroud, T., Karimpooli, S. A Proxy Modeling Approach to Optimization Horizontal Well Placement. American Rock Mechanics Association (2011).

He, Q., Mohaghegh, S. D., Liu, Z. Reservoir Simulation Using Smart Proxy in SACROC UnitCase Study. SPE Eastern Regional Meeting, (13-15 September), Canton, Ohio (2016). http: //dx.doi.org/10.2118/184069-MS.

Hinterding, R., Michalewicz, Z., Eiben, A. E. Adaptation in evolutionary computation: a survey. In IEEECEP: proceeding of the IEEE conference on EC, IEEE world congress on computational intelligence (1997). http://dx.doi.org/10.1109/ICEC.1997.592270.

Kabir, C. S., N. I. Mohammed, and M. K. Choudhary. Lessons Learned From Energy Models: Iraq's South Rumaila Case Study. SPE Middle East Oil and Gas Show and Conference, Manama, Bahrain (2007). http://dx.doi.org/10.2118/105131-MS.

Kooperberg, C. Multivariate Adaptive Regression Splines. Encyclopedia of Environmetrics. 4 (2006).

Lazic, Z. R. Design of experiments in chemical engineering. Wiley-Vch (2006).

Lee, T. H., Lee, C. S., Jung, J., Kim, H-W., Hong, S., Choi, J. Prediction of the Motion of Tracked Vehicle On Soft Soil Using Kriging Metamodel. Fifth ISOPE Ocean Mining Symposium, Tsukuba, Japan (2003).

Lenth, R. V. Response-Surface Methods in R, using RSM. Journal of Statistical Software 32(7), $1-17(2009)$.

McKay, M.D., Beckman, R.J., Conover, W.J. A Comparison of Three Methods for Selecting Values of Input Variables in the Analysis of Output from a Computer Code. Technometrics (JSTOR Abstract) (American Statistical Association) 21 (2): 239-245 (1979). http://dx.doi.org/10. $2307 / 1268522$.

Milborrow. S. Package 'earth'. (2016). Available. https://cran.r-project.org/web/packages/ earth/earth.pdf. 
Mohammed, W. J, Al Jawad, M. S. and D. A. Al-Shamaa. Reservoir Flow Simulation study for a Sector in Main Pay-South Rumaila Oil Field. SPE Oil and Gas India Conference and Exhibition, Mumbai, India (2010). http://dx.doi.org/10.2118/126427-MS.

Montgomery, D. C. and G. C. Runger. Applied Statistics and Probability for Engineers. 3rd Edition. John Wiley and Sons, INC (2003).

Natekin A., Knoll, A. Gradient boosting machines, a tutorial. Frontiers in neurorobotics, vol. 7 (2013). http://dx.doi.org/10.3389/fnbot.2013.00021.

Osterloh, W. T. Use of Multiple-Response Optimization To Assist Reservoir Simulation Probabilistic Forecasting and History Matching. SPE Annual Technical Conference and Exhibition, (21-24 September), Denver, Colorado (2008). http://dx.doi.org/10.2118/116196-MS.

Rao, D.N. Gas-Assisted Gravity Drainage Process for Improved Oil Recovery. United States patent $8,215,392$ B2 (2012).

Rao, D. N., S. C. Ayirala, and M. M. Kulkarni. Development of Gas-Assisted Gravity Drainage (GAGD) Process for Improved Light Oil Recovery. SPE/DOE Symposium on Improved Oil Recovery, (17-21 April), Tulsa, Oklahoma (2004). http://dx.doi.org/10.2118/89357-MS.

Ridgeway, G. Generalized Boosted Models: A guide to the gbm package. (2007). Available: http: //www. saedsayad.com/docs/gbm2.pdf.

Samui, P. Multivariate Adaptive Regression Spline (Mars) for Prediction of Elastic Modulus of Jointed Rock Mass. Geotech. Geol. Eng., 31, 249 (2013). http://dx.doi.org/10.1007/ s10706-012-9584-4.

Stein, M. Large Sample Properties of Simulations Using Latin Hypercube Sampling. Technometrics. 29, 143-151 (1987). http://www.jstor.org/stable/1269769.

Stocki, R. A method to improve design reliability using optimal Latin hypercube sampling. Computer Assisted Mechanics and Engineering Sciences. 12, 87-105 (2005).

Vanegas Prada, J. W., Cunha, L. B. Prediction of SAGD Performance Using Response Surface Correlations Developed by Experimental Design Techniques. Petroleum Society of Canada (2008). http://dx.doi.org/10.2118/08-09-58.

White, C.D., and S.A. Royer. Experimental Design as a Framework for Reservoir Studies. SPE Reservoir Simulation Symposium, Houston, Texas (2003). http://dx.doi.org/10.2118/79676-MS.

Yang, C., Card, C., Nghiem, L. X., and Fedutenko, E. Robust optimization of SAGD operations under geological uncertainties. SPE Reservoir Simulation Symposium, 21-23 February, The Woodlands, Texas (2011). http://dx.doi.org/10.2118/141676-MS.

Yeten, B., Castellini, A., Guyaguler, B., Chen, W. H. A Comparison Study on Experimental Design and Response Surface Methodologies. SPE Reservoir Simulation Symposium, (31 January-2 February), The Woodlands, Texas (2005). http://dx.doi.org/10.2118/93347-MS. 
Zangl, G., Graf, T., Al-Kinani, A. Proxy Modeling in Production Optimization. SPE Europec/EAGE Annual Conference and Exhibition, (12-15 June), Vienna, Austria (2006). http://dx.doi.org/ 10.2118/100131-MS.

Zerpa, L. E., Queipo, N. V., Pintos, S., Tillero, E., Alter, D. An Efficient Response Surface Approach for the Optimization of ASP Flooding Processes: ASP Pilot Project LL-03 Reservoir. SPE Latin American \& Caribbean Petroleum Engineering Conference, (15-18 April), Buenos Aires, Argentina (2007). http://dx.doi.org/10.2118/107847-MS.

Zubarev, D. I. Pros and Cons of Applying a Proxy Model as a Substitute for Full Reservoir Simulations. SPE Annual Technical Conference and Exhibition, New Orleans, Louisiana (2009). http://dx.doi.org/10.2118/124815-MS. 